\title{
Quantification of Leishmania major parasites in dendritic cells deficient for IL-4Ra signalling in BALB/C mice
}

\author{
James L. van Duuren ${ }^{1}$, Frank Brombacher ${ }^{2}$, Ramona Hurdayal ${ }^{3}$ \& Suraj P. \\ Parihar $^{4}$ \\ VDRJAM001@myuct.ac.za ${ }^{1}$ \\ Frank.brombacher@uct.ac.za ${ }^{2}$ ORCID: orcid.org/0000-0001-8881-6781 \\ ramona.hurdayal@uct.ac.za ${ }^{3}$ ORCID: orcid.org/0000-0001-7758-521X \\ Suraj.Parihar@uct.ac.za ${ }^{4}$ ORCID: orcid.org/0000-0002-4932-7990
}

\author{
Supervisor: Professor Frank Brombacher \\ Co-supervisors: Dr. Ramona Hurdayal \\ Dr. Suraj P. Parihar \\ Department: Division of Immunology
}

\begin{abstract}
Susceptibility and resistance in cutaneous Leishmania major infection, is characterised by induction of distinct subsets of immunological response. BALB/c mice display susceptibility to $L$. major infection, developing $T$ helper 2 (Th2) cell dominated responses with production of cytokines Interleukin-4 (IL-4) and IL-13. In contrast, resistant C57BL/6 mice catalyse Th1 dominated immune responses with increased IL-12 and Interferon-gamma (IFNY). Th1 responses are associated with classical macrophage activation and parasite killing via inducible nitrous oxide synthase(iNOs). Paradoxically IL-4 administration during dendritic (DC) priming has been demonstrated to induce IL-12 production by these DC's and instruct a Th1 dominant response. To elucidate the role of endogenous IL-4 levels on DC mediated $T$ cell education, BALB/C mice deficient for the IL-4 receptor a chain (a receptor shared between IL-4 and IL-13) specifically on $D C s$ were generated by gene rearrangement. These $C D 11 C^{\text {cre }} / L-4 R \alpha^{-1 / 0 x}$ mice show hypersusceptibility to L. major infection with increased footpad swelling, peripheral parasite load and reduced iNOS in both macrophages and DCs. Confocal microscopy shows these DCs to be major etiological factors in disease dissemination due to their migratory capacity and reduced parasite killing functions in the absence of early IL-4Ra mediated response.
\end{abstract}

Keywords: Leishmania major, Leishmaniasis, IL-4Ra, BALB/c, Th1/Th2 


\section{Leishmaniasis}

\section{Clinical Spectrum}

The diverse range of more than 20 protozoan species under the genus Leishmania, of the order Kinetoplastida, act as obligate intracellular parasites that cause a spectrum of distinct disease processes (Pearson and de Queiroz Sousa 1996; Desjeux 1996; Alexander and Satoskar 1999). Human Leishmaniasis is well characterised as a complex vector-spread disease transmitted by infected female sandflies of the genus Phlebotomus (notably P. papasi) in the 'Old world' as well as Lutzomyia in areas of central and Southern America (Desjeux 1996; Warburg et al. 1994). It is important to recognize that while Leishmaniasis is well classified as an infectious disease it is not in fact a single entity but exists rather on a spectrum of clinical manifestation (Reithinger et al. 2007). The distinction between disease subsets is determined by interactions between the specific virulence of the species of parasite initiating infection as well as host immunity (Pearson and de Queiroz Sousa 1996). There are further arguments for the association of ecological and geographical milieu with intensity of infective processes and susceptibility, including variations in sandfly salivary content, and immunomodulation due to ultraviolet radiation during infection. (Nacher 2001; Warburg et al. 1994; Reithinger et al. 2007; Giannini 1986; Garssen et al.1999).

Human Leishmaniasis can thus be divided into the following categories: cutaneous Leishmaniasis $(\mathrm{CL})$ with localised and diffuse forms, mucocutaneous Leishmaniasis (MCL), and visceral Leishmaniasis (VL) (Reithinger et al. 2007; World Health Organisation 2014). (Figure 1).

Cutaneous forms are typical with Leishmania major, L. mexicana and L. tropica, while diffuse cutaneous infections occur with $L$. aethiopica and $L$. amazonensis (Desjeux 1996). These present with ulcerative lesions primarily around the site of parasite inoculation, however they can result in extensive nodular scarring and disfigurement if allowed to disseminate or progress to the chronic stage. Lesions of this type are similar to those occurring with lepromatous leprosy (Desjeux 1996). Mucocutaneous disease is caused by L. panamensis, L. guyanensis and notably L. braziiliensis (Desjeux 1996). 
This form causes widespread mucosal inflammation with extensive destructive ulcerative change to the oronasal, pharyngeal and genital mucosa (Pearson and de Queiroz Sousa 1996; Desjeux 1996). L. donovani and L. infantum typically cause the most severe visceral form of Leishmaniasis also known as Kala-Azar, which is usually fatal if left untreated, yet can also cause mucosal destruction in immunocompromised patients (World Health Organisation 2014; Chance 1981; Pearson and de Queiroz Sousa 1996; Desjeux 1996). This form causes systemic fever, weightloss, anaemia and leukopaenia as well as hepato-splenomegally and hyperglobulinaemia (Chance 1981; Carvahlo and Rocha 1990). An unfortunate consequence following treatment of visceral infection is the possibility of developing a condition called post Kala-Azar dermal Leishmaniasis (PKDL), which is associated with a profuse and scarring macular, papular rash over the face, upper arms and torso (Desjeux 1996; World Health Organisation 2014 (2)). In vertebrates infected with the protozoan e.g. humans parasites reside primarily in cells of the reticuloendothelial system of mononuclear phagocytes (Chance 1981; Carvahlo and Rocha 1990). This evolved feature is conserved among a large number of resistant pathogens whose development can be traced alongside human lineage for thousands of years e.g. Mycobacteerium tuberculosis, Listeria monocytogenes and Salmonella typhimurium.

Leishmaniasis has a large and indeed escalating case incidence worldwide. Despite this, Leishmaniasis has traditionally received minimal support and attention from authorities within the public health and medical research sectors, leading to it being identified as one of the World Health Organisation's (WHO) 17 neglected tropical diseases (World Health Organisation 2014 (3)). This is particularly evident with cutaneous Leishmaniasis due to its low fatality rate; with diseases like malaria and HIV/Aids drawing significantly more research funding (Reithinger et al. 2007).

Cutaneous

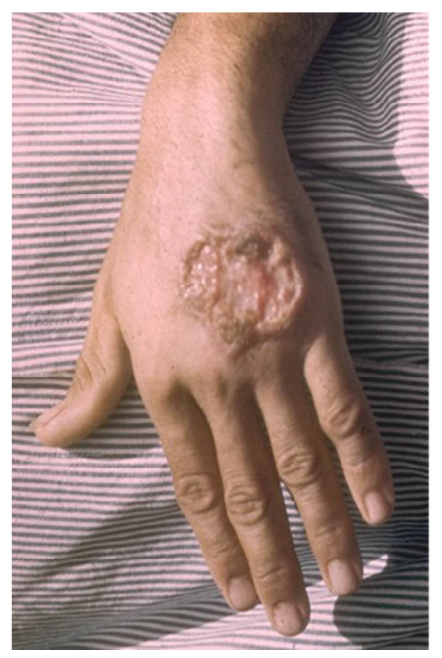

Mucocutaneous

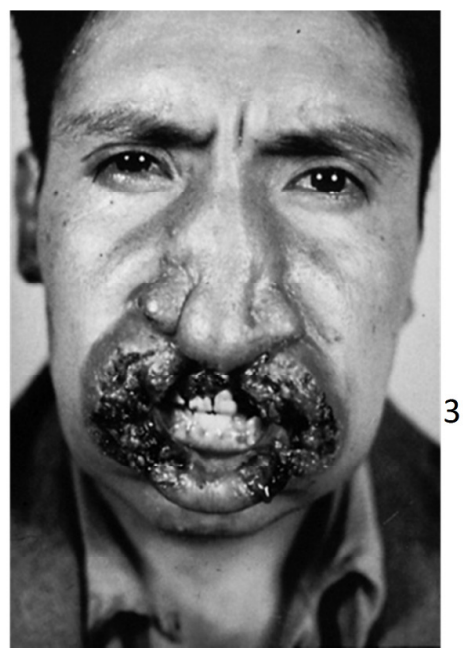

Visceral

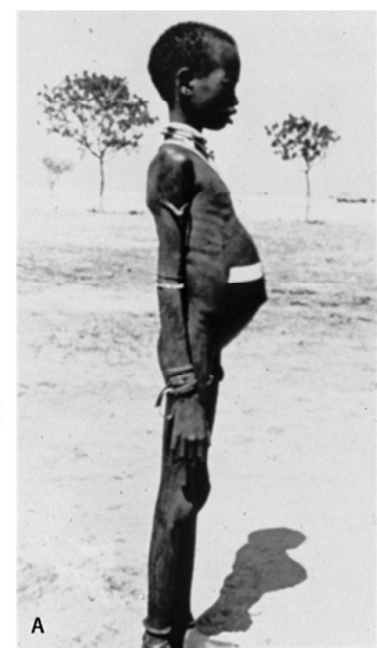

Post Kala-azar dermal Leishmaniasis

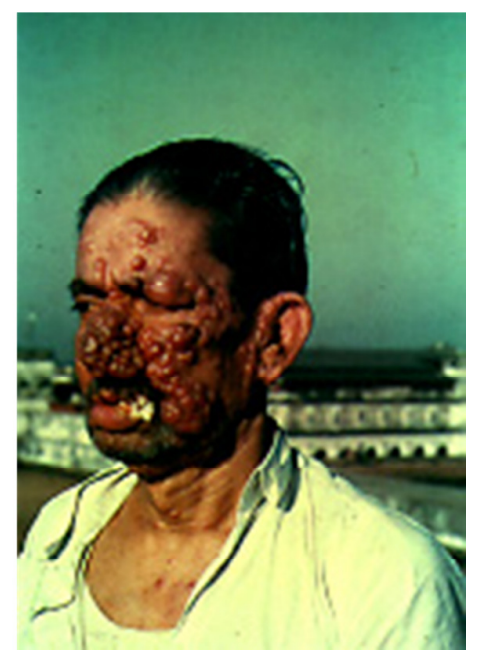


Diagnosis of Leishmania infection is primarily a clinical one with limited scope for smear microscopy to confirm parasitic infection. More specialised diagnostic techniques that characterise pathogen subsets, as exist for Tuberculosis, are not typically available outside of developed countries and research settings due to the high cost considerations (Davies et

al. 2003).

There is currently no vaccine developed for the prevention of any form of Leishmaniasis and treatment is reliant on the use of antibiotic regimens and chemotherapies, chiefly pentavalent antimonials with their high cost and associated adverse reactions e.g. hepatotoxicity and pancreatitis (Reithinger et al. 2005). It is therefore critical that research continues to be advanced in this area.

\section{Epidemiology}

Leishmaniasis is endemic to 88 countries (Desjeux 1996). An estimated 350 million individuals live in areas that place them at risk of infection, with the incidence of cutaneous and visceral Leishmaniasis estimated at 1.0-1.5 million and 500,000 per annum respectively (Pearson and de Queiroz Sousa 1996) (Figure 2). Prevalence is assessed to be near 12 million cases, while WHO records estimate a total of 59000 deaths due to all Leishmaniasis in 2001 (Desjeux 1996; World Health Organisation 2014 (4)). In addition, 2.4 million disability-adjusted life-years (DALYs) were reported (Davies et al. 2003).

As stated, there are more than 20 Leishmania spp. that can cause infection and these are split across ecological niches. The disease is found in areas that can accommodate adequate habitat for vector proliferation and provide a mammalian reservoir for transmission. These are primarily low income rural areas with an estimated $80 \%$ of incident cases earning less than $\$ 2$ per day (Davies et al. 2003). The highest incidences of disease lie in the countries of Bangladesh, India, Brazil, Peru, Sudan, Saudi Arabia, Afghanistan and Iran (Desjeux 1996).

Alarming increases in incidence over recent years highlight critical effects of changing social dynamics on infection. Desjeux (2004) argues that HIV co-infection, urban-rural migration, overcrowding and malnutrition, which drive a 9 times greater risk for VL in children, contribute to elevated incidence. 
Status of endemicity of cutaneous leishmaniasis, worldwide, 2012

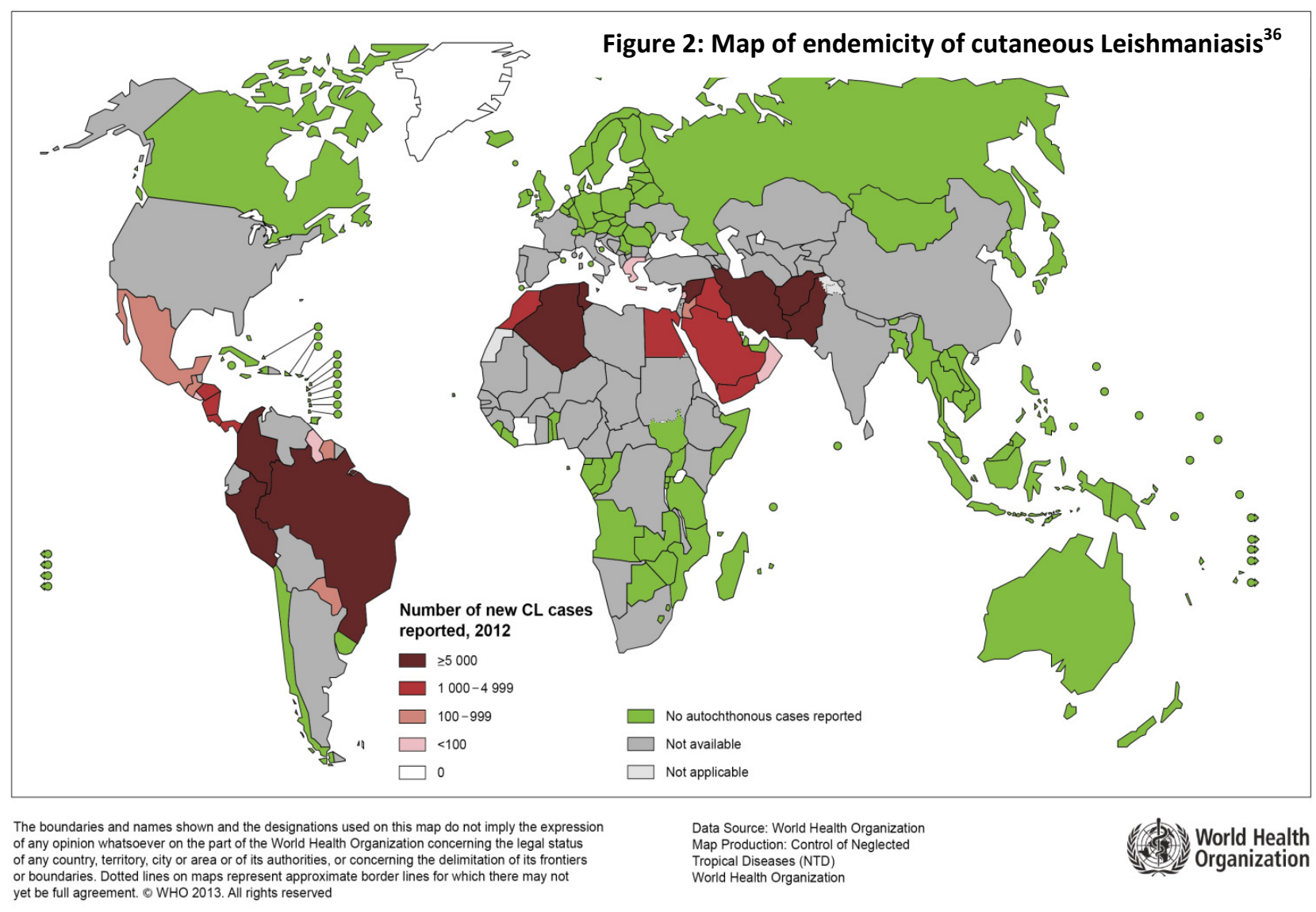

Animal reservoirs are established in both wild and domesticated canine spp., however, L. major and some cutaneous forms are known to have reservoirs in rodents endemic to areas of infection (Chance 1981). There is limited scope for direct humanvector-human transmission in areas of India and East Asia, however, the use of insecticides programs has been shown to successfully control this so-called anthroponotic spread (Chance 1981). Conversely there is evidence that environmental changes, driven by agricultural expansion and deforestation, have caused a movement of vector populations closer to human and domesticated animal reservoirs (Kroeger, Avila and Morison 2002). Thus allowing for an increase in urban incidence in recent years in contradiction to previous predictions (Campbell-Lendrum et al. 2001). 


\section{Life Cycle}

As noted previously female sandflies act as vectors for parasitic infection; parasites thereafter reside in mononuclear phagocytic cells e.g. macrophages. Macrophages containing immotile amastigote ('non-flagellate') forms of parasite are ingested by the sandfly when it takes a blood meal from an infected reservoir population (Pearson and de Queiroz Sousa 1996). Amastigotes undergo differentiation to a flagellated, extracellular procyclic promastigote form in the gut of the sandfly and proliferate (Alexander and Satoskar 1999). Mature non-dividing metacyclic promastigotes migrate towards the fly proboscis within a week (Reithinger et al. 2007).

When a subsequent blood meal is taken these parasites are inoculated (regurgitated) into a new mammalian host, to be rapidly phagocytosed by host immune cells. Thereafter they revert back to the amastigote form within the phagolysosome of macrophages, allowing them to survive within the acidic, hydrolase rich microbicidal environment (Alexander and Satoskar 1999). Cells may eventually rupture to release parasites to infect other cells, thereby continuing the cycle.

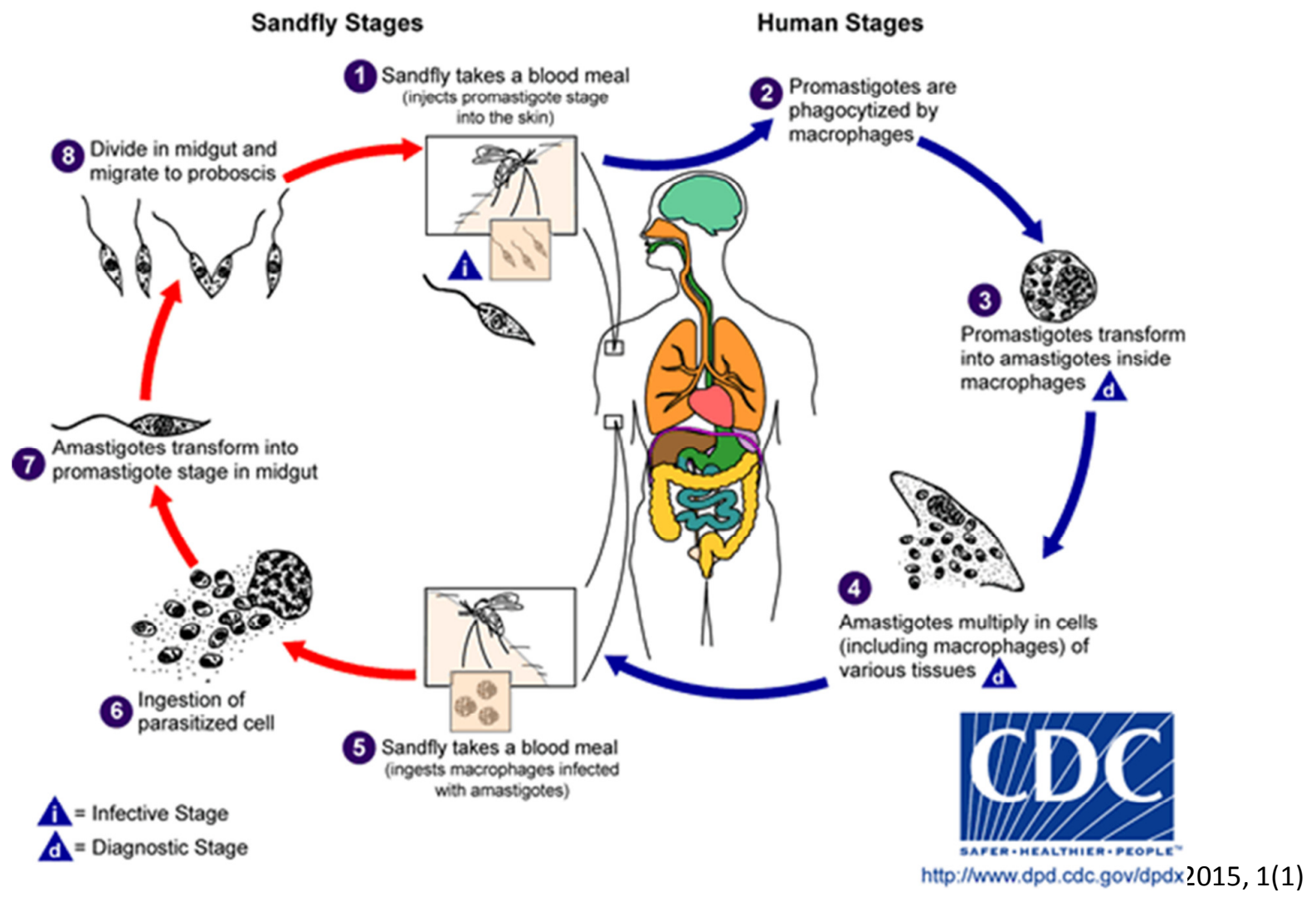

Fig 3: Leishmania infectious and lifecycle in human and sandfly (Sacks and Noben-Trauth 2002). 


\section{Immune response in cutaneous Leishmaniasis}

Intricate host-pathogen interactions account for Leishmaniasis' ability to steer the immune system away from a protective immune response. These interactions are best studied through a well-established in vivo model of resistance and susceptibility in mice. Of these the $L$. major murine model of infection with this cutaneous strain of parasite is foremost in the research (Reithinger et al. 2007).

Natural infection typically involves inoculation of $100-1000$ parasites into the host and results consistently in healing local cutaneous lesions and permanent immunity in humans (Kroeger, Avila, Morison 2002). Infection in the laboratory setting is recreated thorough subcutaneous injection of host animals with a relatively large inoculant $\left(10^{4}-10^{7}\right.$ parasites). Most laboratory mouse spp., including C57BL/6, exhibit healing immunity, however, BALB/C albino mice are not able to exhibit this same protective immune response and degenerate into progressive and disseminated disease (Sacks and NobenTrauth 2002; Hurdayal et al. 2013).

The proposed mechanism behind the development of a susceptible phenotype in BALB/c mice is the polarisation of a T Helper cell type 2 (Th2) immune response (Sacks and Noben-Trauth 2002; Hurdayal et al. 2013; Radwanska 2007). Conversely in resistant mice strains, i.e. C57BL/6 mice, there is evidence of the development of a healing $\mathrm{T}$ Helper type 1 (Th1) response (Sacks and Noben-Trauth 2002; Hurdayal et al. 2013; Radwanska 2007).

$\mathrm{T}$ helper cells act as instructors and coordinators of the immune response by triggering effector functions specific to the type of pathogenic challenge through the secretion of soluble signalling molecules called cytokines. Naïve $T$ cell populations require the presentation of antigenic peptide by antigen presenting cells (APC's), in addition to secondary co-stimulatory molecular signals by these same cells to trigger their activation (Murphy 2012). This functions to prevent immune auto-reactivity with selfantigen. A third signal in the form of cytokines directs the differentiation of the various $T$ cell subsets with their distinct effector functions.

The induction of Th1 responses leads to the dominant expression of the cytokines Interleukin-12 (IL-12), IL-2 and Interferon Gamma (IFNy) which lead to 'classical' 
activation of macrophage effector killing functions via inducible Nitric Oxide synthase (iNOS) production and the formation of Nitric Oxide (NO) (Hurdayal et al. 2013). This response is instructed by the early action of IL-12 on Th development, and is effective in destroying intracellular parasites (Murphy 2012). Evidence suggests that continued IL-12 activity is required to maintain Th1 populations in resistant C57BL/6 mice when challenged with $L$. major infection, even in the absence of a Th2 response (Park et al. 2002). IL-12 administration also stimulates susceptible BALB/c mice to a more than $75 \%$ reduction in parasite load (Sypek et al. 1993). IL-18 is posited to augment IL-12 function (Alexander and Satoskar 1999).

The Th2 type response associated with non-healing infections involves the production of Interleukins IL-4, IL-5, IL-9 and IL-13 among others (Hurdayal et al. 2013; Radwanska 2007). In addition there is a raised anti-Leishmania specific $\lg G 1$ and $\lg E$ titre and alternate activation of macrophages which express Arginase-1, a competitive inhibitor of iNOS (Hurdayal et al. 2013; Radwanska 2007). Parasites are therefore able to thrive in this intracellular environment.

\section{IL-4Ra Signalling}

While a sustained Th2 response is indicative of a susceptible phenotype, resistant C57BL/6 mice also exhibit transient early stage IL-4 production following infection (Sacks and Noben-Trauth 2002; Scott et al 1996). Susceptibility therefore appears to be a result of a failure of immune mechanisms to redirect activated Th2 type responses towards protective Th1 expression (Sacks and Noben-Trauth 2002).

Abrogation of IL-4 signalling with anti-IL-4 antibody leads to a healing response to L. major in BALB/c mice, showing IL-4 to be a major susceptibility factor (Sadick et al. 1990). In addition, Kopf et al. (1996) generated IL-4 deficient BALB/c mice with the same resistant phenotype. However, there is controversy surrounding the extent IL-4's dominance in susceptibility. It has been shown in other studies that IL-4 deficiency was not sufficient to control infection or induce a healing response in BALB/c mice (NobenTrauth, Paul and Sacks 1999; Noben-Trauth, Kropf and Müller 1996). A study confirmed this in different BALB/c lines and parasite strains (Kropf et al. 2003). However, knock-out of IL-4 receptor alpha (IL-4Ra) chain expression could sufficiently control infection with $L$. major strain IR173 (Sacks and Noben-Trauth 2002; Noben-Trauth, Paul and Sacks 
1999). IL-13 shares the IL4R $\alpha$ chain with IL-4 and this evidence suggests a role for IL-13 in susceptibility. Matthews et al showed that IL-13 overexpression could convert resistant mice to a susceptible phenotype and that IL-13 deficiency induced resistance additive to IL-4 deficiency (Matthews 2000). Yet other studies argue that global IL-4Ra knock-out $\mathrm{BALB} / \mathrm{c}$ mice contain infection in the acute phase but succumb to progressive necrosis in chronic stages of infection, unlike IL-4 deficient counterparts (Sacks and Noben-Trauth 2002; Mohrs et al. 1999; Mohrs, Holscher and Brombacher 2000). This paradoxically indicates that IL-13 may have a protective role in chronic infection.

The controversy surrounding IL-4Ra action has opened the way for subsequent experiments investigating the role of this receptor in directing immunity through its deletion on specific cell populations.

It had previously been established that deletion of a specific CD4+ $\mathrm{T}$ cell population displaying the V $\beta 4 \alpha \mathrm{V} 8 \mathrm{~T}$ cell receptor, believed to be responsible for early IL4 production, led to resistance in BALB/c mice (Launois 1997; Sacks and Noben-Trauth 2002). Yet, as previously touched on, resistant strains also appear to have equal early IL4 responses (Sacks and Noben-Trauth 2002). Radwanska et al. (2007) generated CD4+ $T$ cell specific IL4Ra deficient BALB/C mice and showed that these mice exhibited complete resistance to $L$. major equal to their $\mathrm{C} 57 \mathrm{BI} / 6$ counterparts. The fact that this surpasses resistance for global IL-4Ra knockout implies a protective IL-4/IL-13 role on non-CD4+ T cell population.

Macrophage/neutrophil specific IL-4Ra deficient BALB/C mice displayed significantly deferred disease progression with boosted Leishmanicidal activity and reduced alternate activation markers, which signifies that a different phagocytic cell population is at work in promoting resistance via IL-4Ra (Holscher et al 2006).

Dendritic cells (DC's) are defined as highly efficient APCs uniquely capable of directing differentiation of specific Th cell populations from naïve T cell populations (Murphy 2012; Hurdayal 2013; de Jong, Smits and Kapsenburg 2004). Their efficiency arises from their ability to sample large quantities of antigen from peripheral tissues and migrate to lymphoid organs for presentation to activating T cells (Murphy 2012; Hurdayal 2013). DC's were shown to be potent sources of IL-12, capable of inducing Th1 T cell responses (Macatonia 1995; Heufler 1996). Furthermore in-vitro studies have that shown stimulation 
of DC's with IL-4 produces this IL-12 (Hochrein et al. 2000). A landmark paper by Biedermann et al. (2001) confirmed that early IL-4 administration during DC activation against CpG DNA motifs instructed IL-12 production by these DC's in-vitro. This study was extended in-vivo, showing early IL-4 administration to polarise a Th1-dominated resistant phenotype against $L$. major infection in BALB/c mice (Biedermann et al. 2001). IFNy to IL-4 cytokine ratio was increased tenfold in these mice (Biedermann et al. 2001). Conversely, IL-4 present during T cell priming instructed a Th2 response with supressed IL-12 (Biedermann et al. 2001). The IL-4 instruction effect was shown to be dose dependant. Hurdayal et al. (2013) furthered this research by generating DC specific

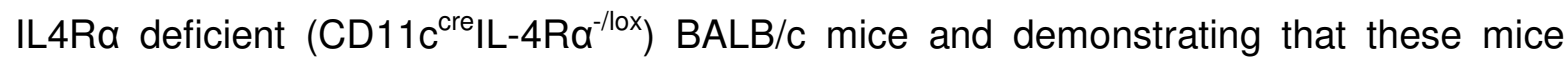
display a hypersusceptible phenotype to $L$. major with biological levels of IL-4 acting on DC's to promote Th1 responses. Hypersusceptibility in these animals included increased footpad swelling, dramatically increased host-cell parasite burden, dissemination and reduced iNOS production in macrophages as well as DC's.

\section{Research Aims and Hypothesis}

DC's are significant in the immune response to Leishmania, yet there is limited knowledge of their precise functioning in this regard. Macrophage populations, however, have long been shown to be the principal hosts of Leishmania parasites (Pearson and de Queiroz Sousa 1996; Alexander and Satoskar 1999; Reithinger et al. 2007). Hypersusceptibility, particularly the high peripheral parasite burden in brain, liver and spleen, shown by the Hurdayal et al. (2013) study, raises questions of whether

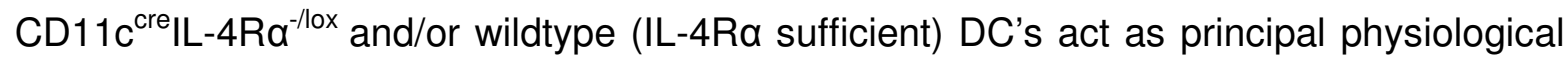
factors in cutaneous disease dissemination by harbouring parasites? If so, do

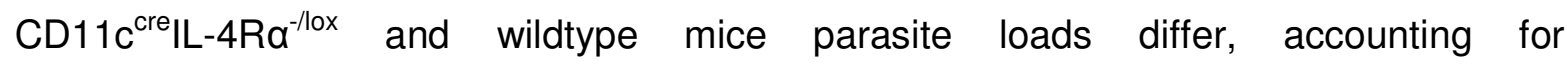
hypersusceptible responses in light of reduced iNOS in knockout DC's? Thus indicating a role for biological IL-4 quantities in mediating DC instruction of protective Th1 responses with the subsequent enhancement of killing effector functions (Biedermann et al. 2001). Macrophages and DC infection rates must also be compared to establish whether these principal phagocytic cells retain higher, lower or similar parasite levels in the IL-4Ra deficient and sufficient BALB/C model. To answer these questions, fluorescent confocal microscopy is used to compare DC's and macrophages in the lymph nodes and spleen of these populations in terms of their intracellular parasite burden. It is hypothesised that IL- 
4Ra deficient DC's harbour high parasite burdens owing to the hypersusceptible response and reduced iNOS levels.

Materials and Methods

Generation and genotyping

Specific DC IL-4Ra deficient BALB/c mice were generated via gene targeting and site-specific recombination by means of the cre/loxP system. This was engaged in the deletion of IL-4Ra gene marked by the lox sequence when in conjunction with the specific expression of the cyclization recombinase (Cre) enzyme in the CD11C+ DC population (Hurdayal et al. 2013; Hurdayal 2013). CD11c codes a transmembrane protein specific to DC's as well as alveolar macrophages. The gene acts as a Cre promoter sequence. Breeding of mouse strains is as covered by Hurdayal et al 2013 (Hurdayal et al. 2013). The generated CD11ccrelL-4Ra-/lox were assessed for IL-4Ra deletion by flow cytometry and gene PCR, showing efficient depletion compared to IL4Ra-/lox littermate controls (Hurdayal et al. 2013). Functional impairment was assessed through stimulation of bone marrow-derived DC's with Lipopolysaccharide in addition IL-4 and/or IL-13.

\section{Infection of CD11c ${ }^{\text {cre }}$ IL-4Ra $\alpha^{-/ l o x}$ mice with L. major}

Genotyped mice were infected with the IL81 (MHOM/IL/81/FEBNI) L. major strain expressing Green Fluorescent Protein (GFP), a fluorescent marker under light stimulation. Mice were anaesthetised and inoculated with $2 \times 10^{6}$ stationary phase metacyclic promastigotes, which had been extracted and cultured from a maintained infected line of BALB/c mice (so-called passage strain) (Hurdayal 2013). All experiments are in accordance with ethical standards (Hurdayal et al. 2013). Footpad swelling was measured weekly with the Mitutoyo micrometer calliper (Brütsch, Zürich, Switzerland).

The virulence of the IL81 parasite required the mice to be killed at 6 weeks following infection. Thereafter popliteal lymph node and spleen samples were extracted for confocal microscopy. Two methods of tissue preparation were employed for comparison. These are covered in depth in Appendix A. Initially samples were directly 
embedded in Optimum Cutting Temperature (OCT) freezing medium and $10 \mu \mathrm{M}$ sections cut on the Cryostat microtome. Pre-fixing was avoided to minimize background fluorescence from the fixing process.. Poor GFP signal intensity on confocal imaging led to new tissue being pre-fixed for 2 hours in $4 \%$ paraformaldehyde and immersed in cryoprotective $30 \%$ sucrose solution, which fills cellular spaces preventing frost formation, prior to embedding.

Staining involved primary CD11C or CD68 antibodies and secondary StreptavidinСy3 fluorescence conjugation for visualisation. Nuclei were counterstained with Hoescht.

\section{Confocal Quantification:}

Slides were viewed acquired with the Ziess LSM 510 confocal microscope (Jena, Germany) (Hurdayal 2013). Multiple 40x zoom, low zoom and tiled 4x4 low zoom images were taken per slide for analysis of parasite load and $\mathrm{DC} /$ macrophage surface marker signal intensity. 


\section{Results}

Pre-fixed and cryoprotected cryo-sections display greater GFP expressing parasite integrity

Pre-fixing was carried out with hopes of minimising structural alteration to GFP signal, thereby reducing background auto-fluorescence and enhancing GFP+ parasite visualisation. Non-fixed and pre-fixed specimens were compared for GFP+ parasite visualization in $L N$ and spleen with the latter displaying greater intensity and clarity for quantification (Fig 4).

A.) No pre-fixing or cryoprotection

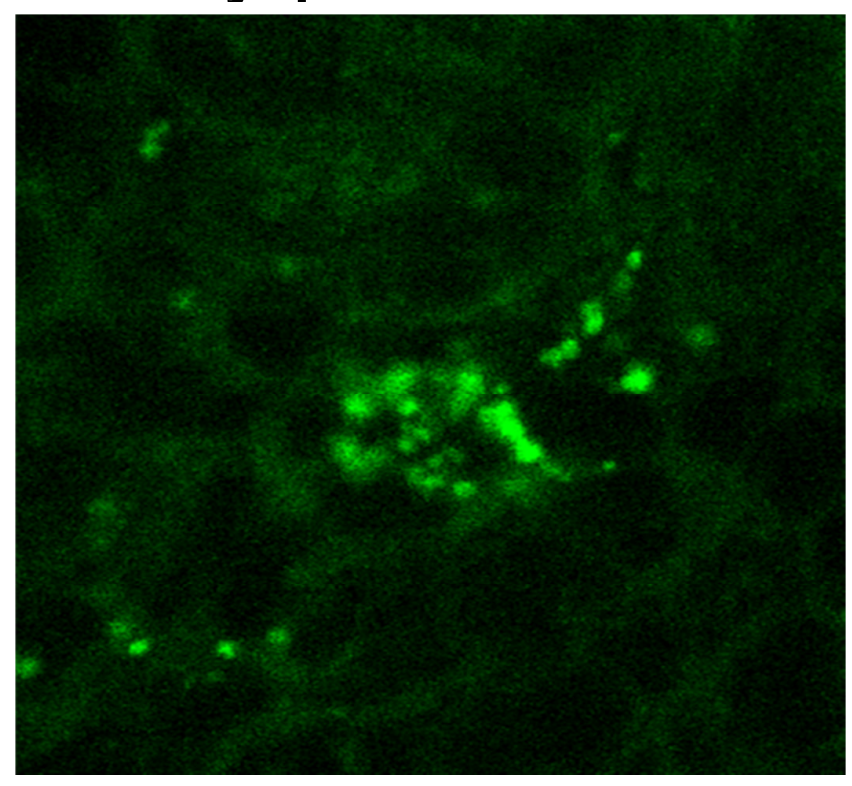

\section{B.) Pre-fixed and cryoprotected}

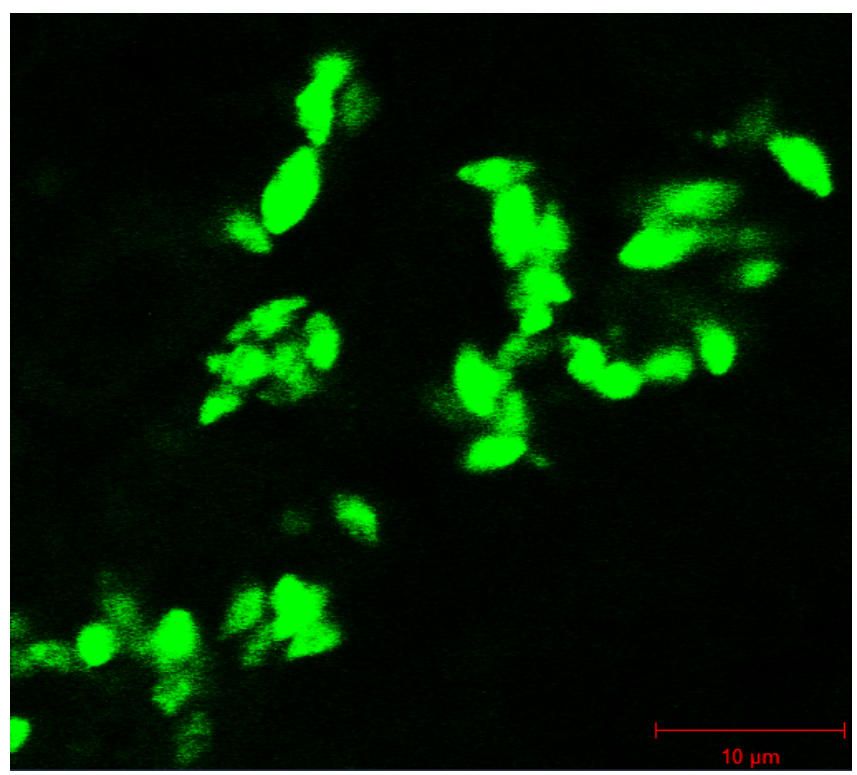

Fig 4: GFP signal integrity for pre-fixed is superior to non-pre-fixed specimens in lymph nodes $\mathrm{CD} 11 \mathrm{c}^{\mathrm{cre}} \mathrm{IL}-4 \mathrm{R} \alpha^{-/ 10 x}$ and littermate control IL-4R $\alpha^{-/ 10 x} \mathrm{BALB} / \mathrm{c}$ mice were generated by gene specific recombination and infected with GFP-expressing L. major IL-81. ${ }^{19}$ Lymph node (LN) and spleen samples were removed 6 weeks after infection and either embedded directly in OCT freezing medium (A) or first prefixed in $4 \%$ PFA for $2 \mathrm{hrs}$ at $4^{\circ} \mathrm{C}$ followed by cryoprotection in $30 \%$ sucrose solution overnight and prior to OCT embedding on dry-ice freeze (B). AEPES coated slides were prepared with $10 \mu \mathrm{M}$ cryo-sections for visualisation by confocal microscopy of the presence of GFP+ L. major. Representative $L N$ images shown indicate the dramatic increase in signal quality. 
Comparison of macrophage and DC cell-specific marker staining Intensity of macrophage and DC specific CD68 and CD11c fluorescent markers was

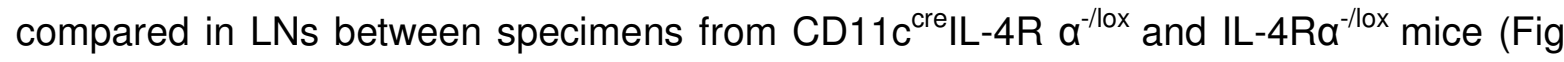
5). DCs in $C D 11 c^{\text {cre } I L-4 R ~} a^{-/ 10 x}$ mice showed higher $D C$ surface marker intensity than littermates. Similarly macrophages from $\mathrm{CD} 11 \mathrm{c}^{\text {cre }} \mathrm{IL}-4 \mathrm{R} \mathrm{a}^{-/ 10 x}$ displayed higher CD68 intensity than littermates. Macrophage CD68 marker intensity was uniformly higher than DC CD11c in knockouts and littermates.

\section{Intensity of Cell-specific Staining}

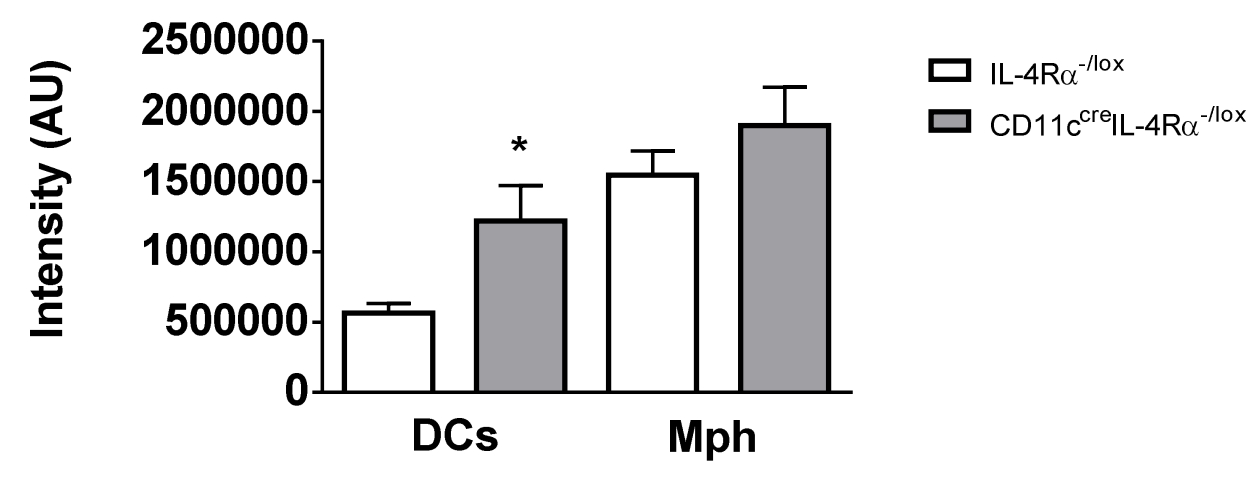

Fig 5: DC specific IL-4R $\alpha$ knock-out BALB/c mice display increased macrophage and DC surface marker expression in $\mathrm{LN}$

$\mathrm{CD} 11 \mathrm{c}^{\mathrm{cre}} \mathrm{IL}-4 \mathrm{R} \alpha^{-/ l o x}$ and littermate control IL-4R $\alpha^{-/ / \mathrm{lox}} \mathrm{BALB} / \mathrm{C}$ mice were generated by gene specific recombination and infected with GFP-expressing L. major IL-81. ${ }^{19} \mathrm{LN}$ and spleen samples were removed 6 weeks after infection and prepared as $10 \mu \mathrm{M}$ cryo-sections. DC's and macrophages were stained with cell-specific biotinylated CD11c and biotinylated CD68 respectively. Cells were stained with Streptavidin-Cy3. Intensity of confocal imaging was compared with MatLab software. Data is expressed as mean \pm SEM. Statistical analysis was performed defining differences to IL-4R $\alpha^{-/ l o x}$ mice $(*, p \leq 0.05)$.

\section{Parasite burden is raised in LN of DC specific IL-4Ra deficient mice}

Confocal imaging was used to quantify the LN parasite load in DCs and macrophages of $\mathrm{CD} 11 \mathrm{c}^{\mathrm{cre}} \mathrm{IL}-4 \mathrm{R} \alpha^{-/ 10 x}$ and IL-4Ra $\alpha^{-/ 10 x}$ mice. Representative images display striking increases in GFP+ parasite loads in CD11 $\mathrm{c}^{\text {cre }} \mathrm{IL}-4 \mathrm{Ra}{ }^{- \text {llox }}$ mice (Fig 6). Clear 
associations between high cell-specific CD11c and CD68 marker fluorescence and GFP+ parasite are visible indicating the intracellular nature of much of the parasite.

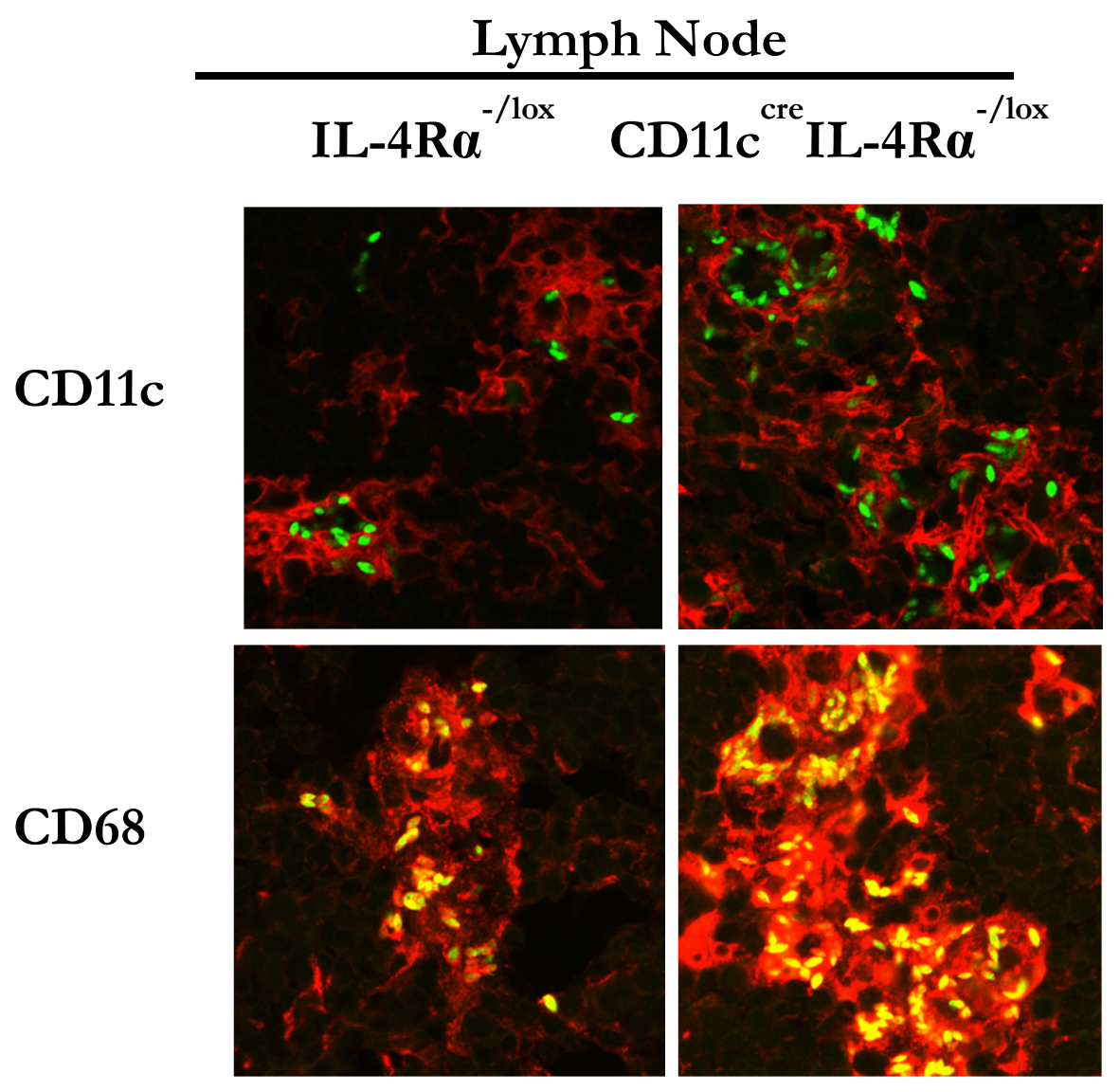

Fig 6: Representative low zoom confocal images in LNs showing dramatically increased parasite burden in CD11 $c^{\text {cre }} \mathrm{IL}-4 \mathbf{R}^{-/ 10 x}$ BALB/c mice over littermate control IL-4R $\alpha^{-/ / 0 x}$ GFP signalling is shown in green, while cell-specific macrophage and DC markers stained with biotinylated CD68 and CD11c respectively and then with Streptavidin-Cy3 are shown as red fluorescence. ${ }^{19}$ Clear association between GFP parasite and cell markers indicates the close proximity ad intracellular nature of much of the parasite. Co-localization of parasite and cell generates a combined fluorescent spectrum i.e. yellow markings.

\section{Manual Counts}

Manual GFP+ parasite counts were performed on LN samples. DCs and macrophages from $\mathrm{CD} 11 \mathrm{c}^{\mathrm{cre}} \mathrm{IL}-4 \mathrm{R} \alpha^{-/ 10 x}$ mice both displayed increased parasite burdens over littermate IL-4Ra ${ }^{-/ 10 x}$ mice (Fig 7). 


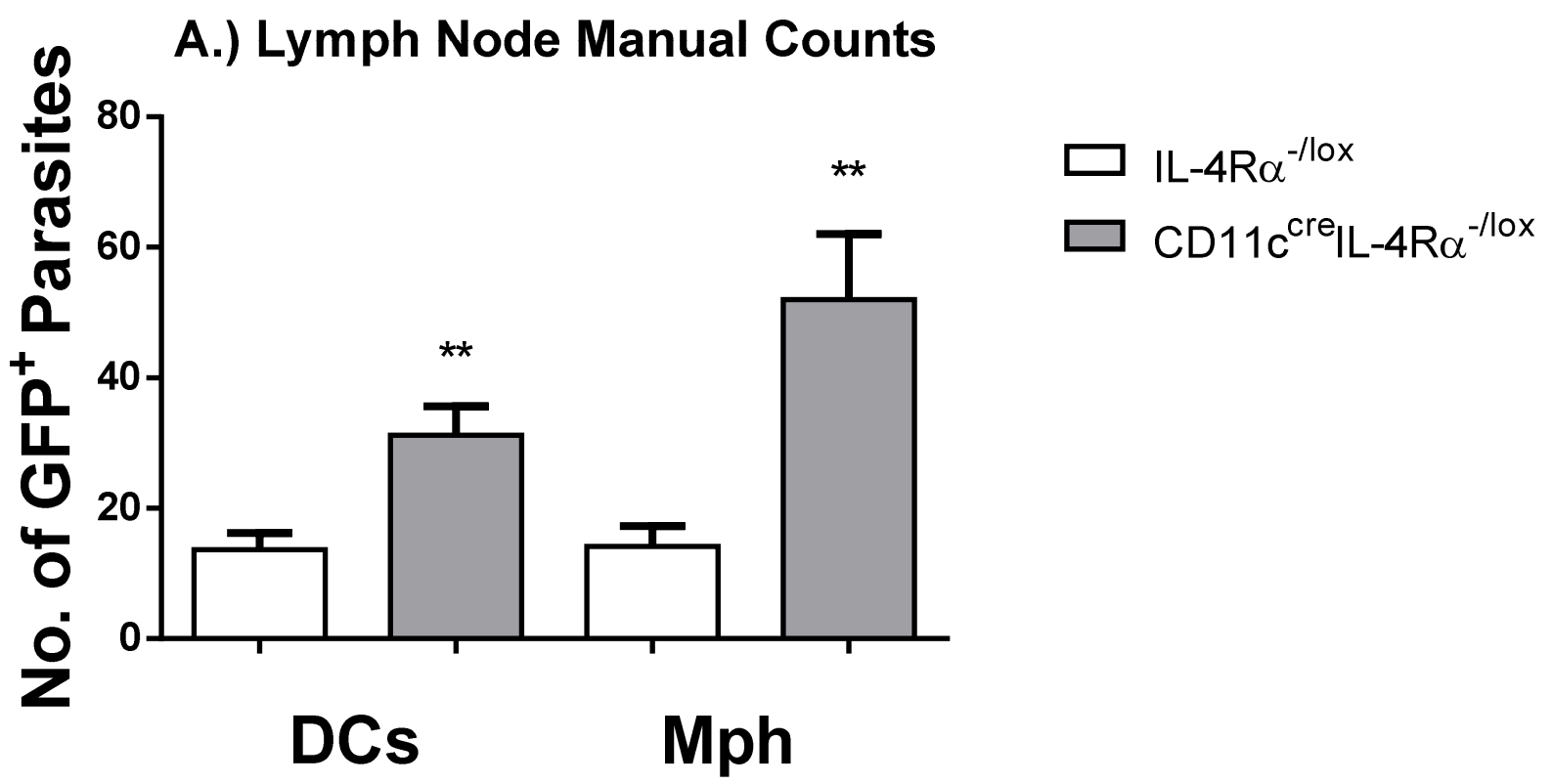

Fig 7: DC specific Il-4R $\alpha$ deficient BALB/c mice show trend of increased parasitic load over littermates in lymph nodes:

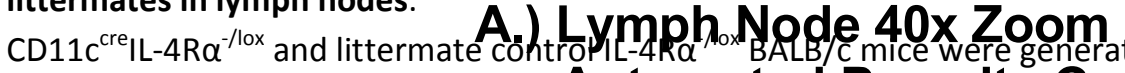

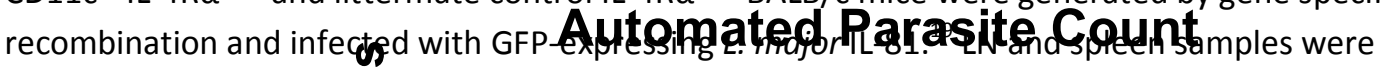
removed 6 weeks after 10 ectionond prepared as $10 \mu \mathrm{M}$ cryo-sections. Cell-specific macrophage and

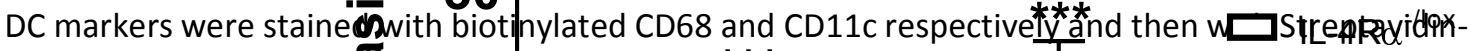

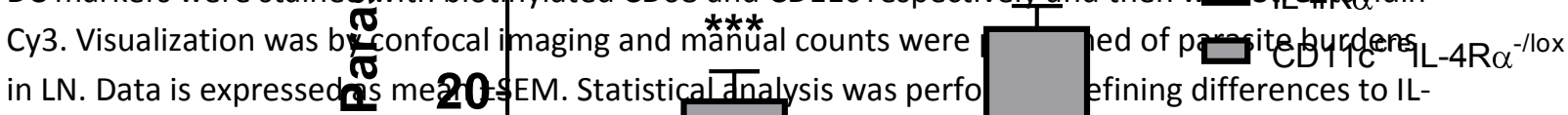
$4 R^{-/ 10 x}$ mice $\left(^{* *}, p \leq 0.0+\right)$.

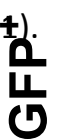

using 4 官 manual counts (Fig 8). 40x zoom images (Fig 8 A) as for low zoom 4x4 image tiles (Fig 8 B).
Automated quantification MatLab software further confirmed results obtained by Mph The observed trend was the same for

\section{B.) Lymph Node Tiled 16 Field Automated Count}
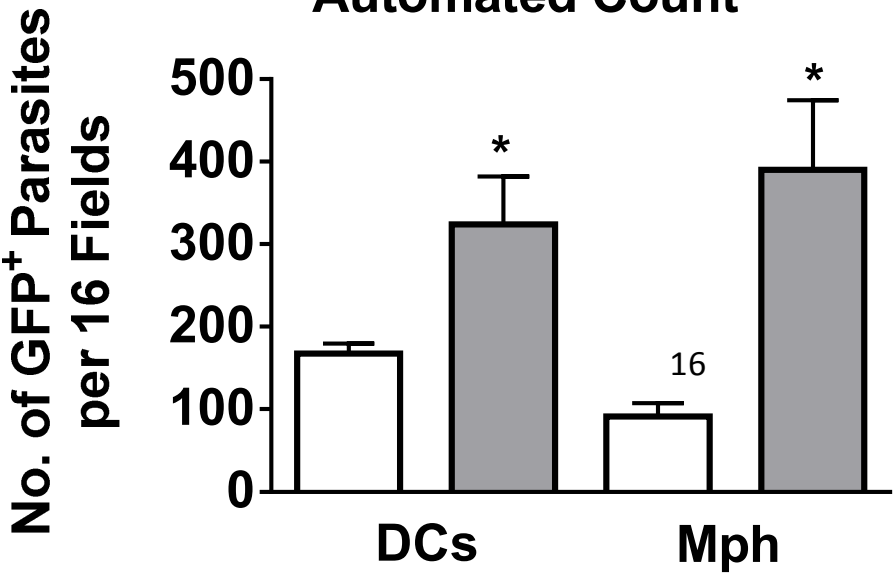
http://journals.uct.ac.za/index.php/UR

DOI 10.15641/ur-at-uct.v1i1.29

Fig 8: DC specific IL-4Ra BALB/c mice show significant increase in L. major parasite burden in lymph nodes

$\mathrm{CD} 11 \mathrm{c}^{\mathrm{cre}} \mathrm{IL}-4 \mathrm{R} \alpha^{-/ / 10 x}$ and littermate control IL-4R $\alpha^{-/ 10 x} \mathrm{BALB} / \mathrm{c}$ mice were generated by gene specific recombination and infected with GFP-expressing L. major IL-81 (Hurdayal et al. 2013). LN and spleen samples were removed 6 weeks after infection and prepared as $10 \mu \mathrm{M}$ cryo-sections. Visualization was by confocal imaging and automated quantification of parasite burdens in tiled $4 \times 4$ low zoom fields and 40x zoom was performed by Rethabile Kutlang of CSIR Pretoria using MatLab software. Data is expressed as mean \pm SEM. Statistical analysis was performed defining differences to IL-4R $\alpha$ /lox mice $(*, p \leq 0.05, * * *, p \leq 0.001)$. 
DC specific IL-4Ra deficient BALB/c mice show higher levels of disseminated parasite in DCs and macrophages in the spleen

Confocal imaging revealed higher parasite loads in DCs and macrophages of $\mathrm{CD} 11 \mathrm{C}^{\mathrm{cre}} \mathrm{IL}-4 \mathrm{Ra}^{-/ 10 x}$ and IL-4Ra ${ }^{-/ / 0 x}$ mice in the spleen. Representative images show high association between GFP+ parasites and cell-specific surface markers CD11C and CD68 indicating parasites to be predominantly intracellular (Fig 9).

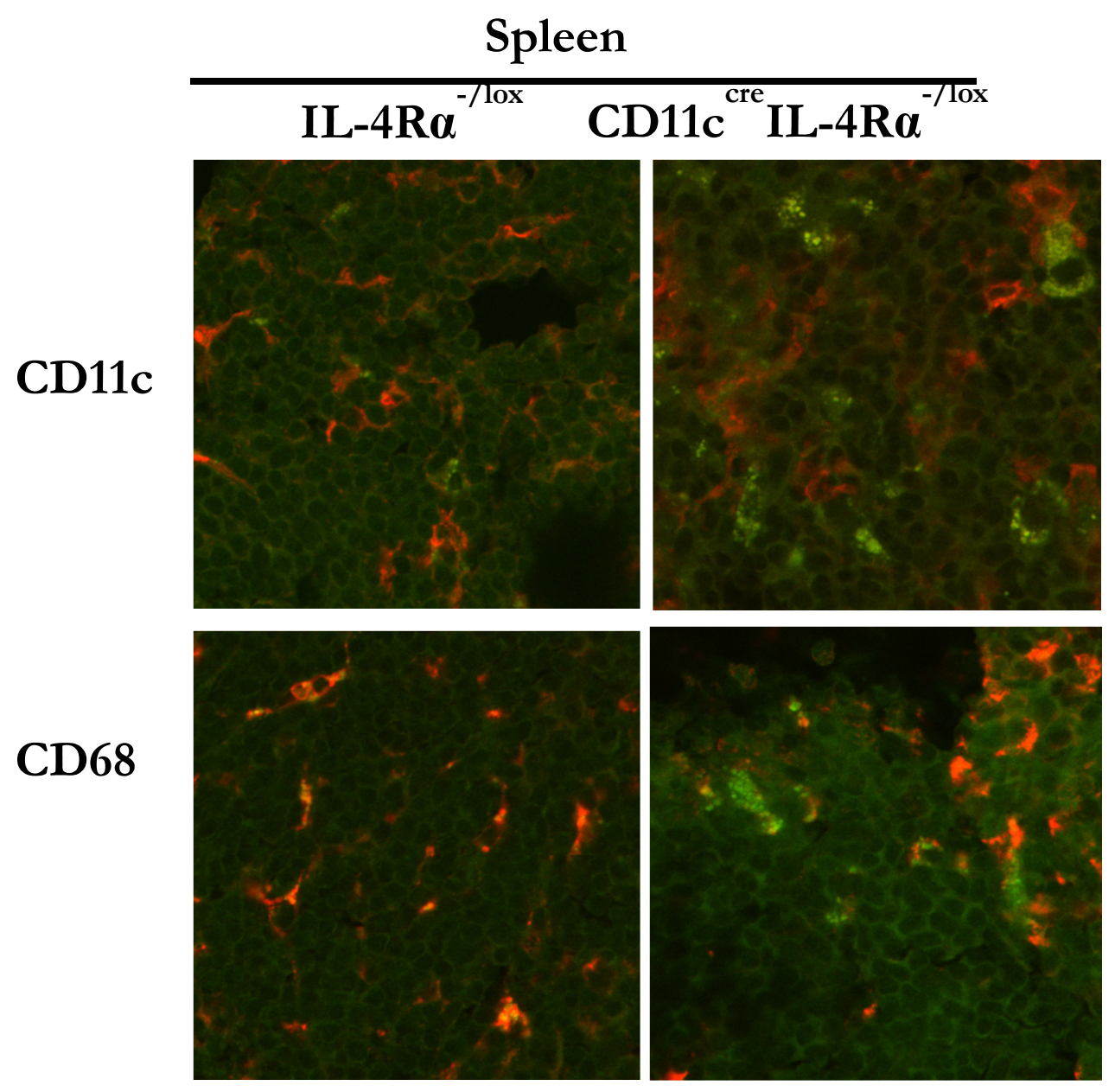


Fig 9: Representative low zoom confocal images in LNs showing dramatically increased parasite burden in CD11 $c^{\text {cre }}$ IL-4R $\alpha^{-/ 10 x}$ BALB/c mice over littermate control IL-4R $\alpha^{-/ / 10 x}$ GFP signalling is shown in green, while cell-specific macrophage and DC markers stained with biotinylated CD68 and CD11c respectively and then with Streptavidin-Cy3 are shown as red fluorescence (Hurdayal et al. 2007). Clear association between GFP parasite and cell markers indicates the close proximity ad intracellular nature of much of the parasite. Co-localization of parasite and cell generates a combined fluorescent spectrum i.e. yellow markings.

Manual GFP + parasite counts were performed on spleen confocal samples with DCs and macrophages from $\mathrm{CD} 11 \mathrm{c}^{\mathrm{cre}} \mathrm{IL}-4 \mathrm{R} \alpha^{-/ / 0 x}$ mice both displaying increased parasite burdens over littermate IL-4Ra ${ }^{- \text {/lox }}$ mice (Fig 10).

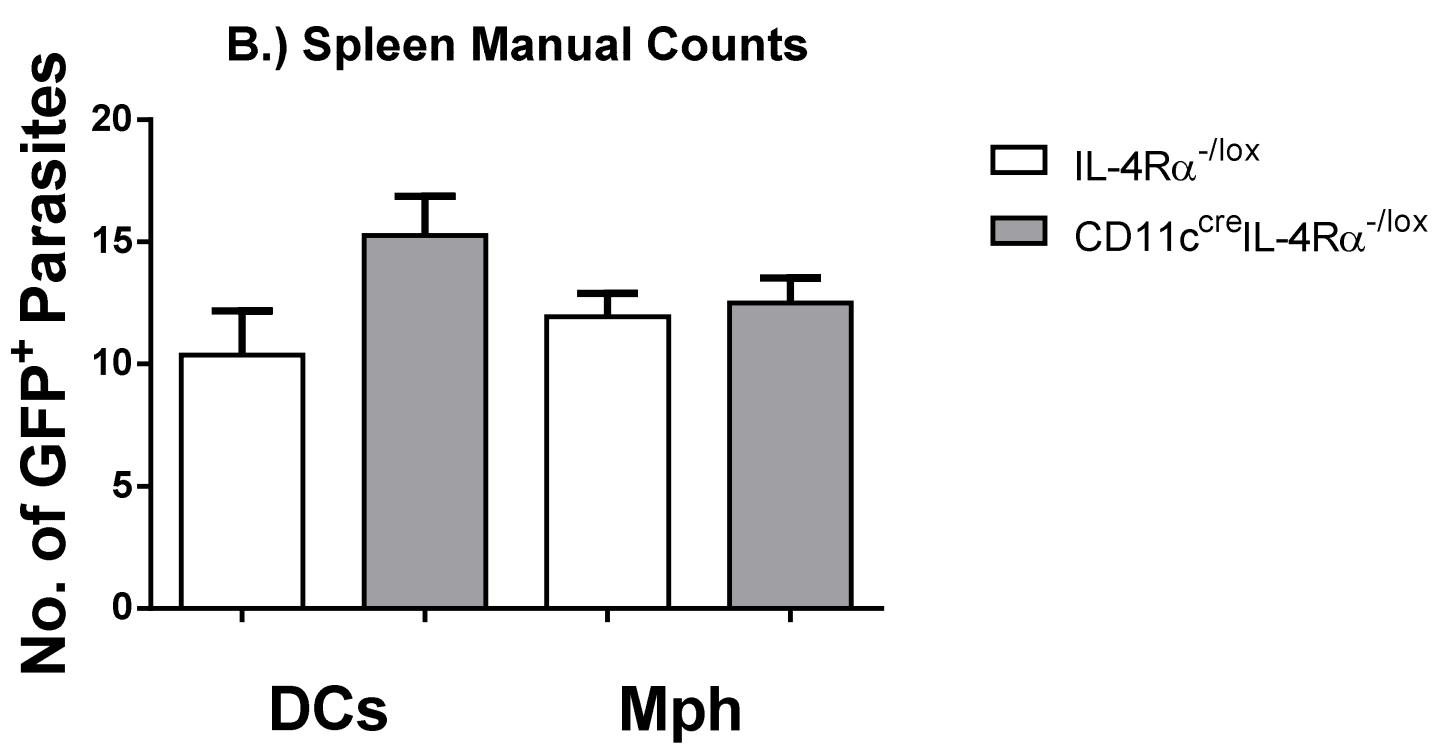

Figure 10:

\section{Discussion}

The classical Th1 vs Th2 dogma that has dominated much of immunological research has been consistently challenged by discoveries in the field of cutaneous Leishmaiasis. II-4, a Th2 cytokine has been shown to induce DC instruction of a Th1 phenotype in BALB/C mice protective against $L$. major when administered during DC priming (Hurdayal 2013). 
To address the role of biological levels of IL-4, DC specific IL-4Ra deficient BALB/c mice were infected with L. major IL81. (see methods). These mice displayed a hypersusceptible phenotype with progressive disease development, increased parasite loads and decreased iNOS induction.

Histological and FACS analysis had confirmed the dissemination of increased parasite loads to peripheral tissues in knockout mice (Campbell-Lendrum 2001; Hurdayal 2013): However as dendritic cells are known to be highly specialised to migrate for antigen presentation, it has been hypothesised that this may be the mechanism by which parasites disseminate (Murphy 2012). This is backed-up by evidence of reduce iNOS in both DCs and macrophages of the CD11 $\mathrm{c}^{\text {cre }} \mathrm{IL}-4 \mathrm{Ra}^{-/ 10 x}$ population (Hurdayal et al. 2013; Hurdayal 2013). Reduced iNos is a sign of reduced classical DC activation and implies parasites are able to maintain their existence within principle phagocyte populations (De Trez 2009). Flow cytometry could not be used to differentiate between intracellular and closely associated but extracellular parasites in macrophage and DC populations to determine which in fact plays the major role in disease progression in IL-4Ra deficient/sufficient mice. Thus confocal microscopy was carried out, co-localisation of signals is used to identify intracellular parasite presence

\section{Conclusion}

Pre-fixing and cryo-protecting samples was shown to reduce confocal autofluorescence and thus enhance visualization of parasite. This enabled greater clarity of imagery for quantification thus generating more accurate data trends. Parasite loads in $\mathrm{CD} 11 \mathrm{C}^{\mathrm{cre}} \mathrm{IL}-4 \mathrm{Ra}^{-1 / 0 x}$ mice were notably higher than littermates indicating hypersusceptibility is correlated with increased parasite burden. Furthermore the intracellular amastigote form of the parasite was rendered visible by the confocal microscope showing confirmation that parasites were within cells. Although both macrophages and DCs had higher parasite loads in the knockout mice model, macrophages had higher loads overall. One might think that this is simple in keeping with their known major role as parasite hosts, however, signalling intensity of macrophage CD68 in higher than DC CD11C marker. This intensity is proportional to the cell population, macrophages have their parasite load spread over a significantly higher population of cells. Therefore we can conclude that in is DC's that in fact carry the major 
burden of $L$. major acting as safe havens for parasites as well as mechanisms of disease dissemination.

\section{Reference List:}

Alexander, J., Satoskar, A.R., Russell, D.G. 1999. Leishmania species: model of intracellular parasitism. Journal of Cell Biology, 112:2993-3002.

Andrade, T.M., Carvahlo, E.M., Rocha, H. 1990. Bacterial infections in patients with visceral Leishmaniasis. Journal of Infectious Diseases, 162(6):1354-1359.

Biedermann, T., Zimmermann, S., Himmelrich, H., Gumy, A., Egeter, O., Sakrauski, A.K. et al. 2001. IL-4 instructs TH1 responses and resistance to Leishmania major in susceptible BALB/c mice. Nature Immunology, 2(11):1054-1060.

Campbell-Lendrum, D., Dujardin, J.P., Martinez, F., Feliciangeli, M.D., Perez, J.F., Dejeux, P. 2001. Domestic and peridomestic transmission of american cutaneous Leishmaniasis: changing epidemiological patterns present new control opportunities. Memórias do Instituto Oswaldo Cruz, 96(2):159-162.

Chance, M.L. 1981. The six diseases of WHO. British Medical Journal, 283, 1245-1247.

Davies, C.R., Kaye, P., Croft, S.L., Sundar, S. 2003. Leishmaniasis: new approaches to disease control. British Medical Journal, 326:377-382.

De Jong, E.C., Smits, H.H., Kapsenberg, M.L. 2004. Dendritic cell mediated T cell polarisation. Springer Seminars in Immunopathology, 26:289-307.

Desjeux, P. 1996. Leishmaniasis: public health aspects and control. Clinical Dermatology, 14(5):417-423.

Desjeux, P. 2004. Leishmaniasis: current situation and new perspectives. Comparative Immunology, Microbiology and Infectious Diseases, 27(5):305-318. 
De Trez, C., Magez, S., Akira, S., Ryffel, B., Carlier, Y., Muraille, E.. 2009. iNOSproducing inflammatory dendritic cells constitute the major infected cell type during the chronic Leishmania major infection phase of C57BL/6 resistant mice. PLOS Pathogens, 6(5):1-13.

Garssen, J., Vandebriel, R.J., De Gruijl, F.R., Wolvers, D.A.W., van Dijk, M., Fluitman, A., et al. 1999. UVB exposure-induced systemic modulation of Th1- and Th2-mediated immune responses. Immunology, 97(3):508-514.

Giannini, M.S.H. 1986. Suppression of pathogenesis in cutaneous Leishmaniasis by UV irradiation. Infection and Immunity, 51(3):838-845.

Heufler, C., Koch, F., Stanzl, U., Topar, G., Wysocka, M., Trinchieri, G., et al. 1996. Interleukin-12 is produced by dendritic cells and mediates $\mathrm{T}$ helper 1 development as well as interferon-gamma production by $\mathrm{T}$ helper 1 cells, European Journal of Immunology, 26(3), 659-668.

Hochrein, H., O’Keeffe, M., Luft, T., Vandenebeele, S., Grumont, R.J., Maraskovsky, E. 2000. Interleukin (II)-4 is a major regulatory cytokine governing bioactive IL-12 production by mouse and human dendritic cells. The Journal of Experimental Medicine, 192(6):823834.

Holscher, C., Arendse, B., Schwegmann, A., Myburgh, E., Brombacher, F. 2006. Impairment of alternative macrophage activation delays Cutaneous Leishmaniasis in nonhealing BALB/c mice. Journal of Immunology, 176:1115-1121.

Hurdayal, R. 2013. Deletion of IL-4 receptor alpha on dendritic cells renders BALB/c mice hypersusceptible to Leishmania major infection. UCT IIDMM, Cape Town.

Hurdayal, R., Nieuwenhuizen, N.E., Revaz-Breton, M., Smith, L., Hoving, J.C., Parihar, S.P., et al. 2013. Deletion of IL-4Ra on dendritic cells renders BALB/c mice hypersusceptible to Leishmania major infection. PLOS Pathogens, 9(10):1-15.

Kopf, M., Brombacher, F., Kohler, G., Kienzle, G., Widmann, K.H., Lefrang, A., et al. 1996. IL-4-deficient Balb/c mice resist infection with Leishmania major. Journal of Experimental Medicine, 184:1126-1137. 
Kroeger, A., Avila, E.V., Morison, L. 2002. Insecticide impregnated curtains to control domestic transmission of cutaneous Leishmaniasis in Venezuela: cluster randomised trial. British Medical Journal, 325:810-813.

Kropf, P., Herath, S., Weber, V., Modolell, M., Müller, I. 2003. Factors influencing Leishmania major infection in IL-4-deficient BALB/c mice. Parasite Immunology, 25(89):439-447.

Launois, P., Maillard, I., Pingel, S., Swihart, K.G., Xénarios, I., Acha-Orbea, H., et al. 1997. IL-4 rapidly produced by $\vee$ beta $4 \mathrm{~V}$ alpha $8 \mathrm{CD} 4+\mathrm{T}$ cells instructs Th2 development and susceptibility to Leishmania major in BALB/c mice. Immunity, 6(5):541549 .

Macatonia, S.E., Hosken, N.A., Litton, M., Vieira, P., Hsieh, C.S., Culpepper, J.A., et al. 1995. Dendritic cells produce IL-12 and direct the development of Th1 cells from naive CD4+ T cells. Journal of Immunology, 154(10):5071-5079.

Matthews, D.J., Emson, C.L., McKenzie, G.J., Jolin, H.E., Blackwell, J.M., McKenzie, A.J.N. 2000. IL-13 is a susceptibility factor for Leishmania major infection. Journal of Immunology, 164(3):1458-1462.

Mohrs, M., Holscher, C., Brombacher, F. 2000. Interleukin-4 receptor alpha-deficient BALB/c mice show an unimpaired T helper 2 polarization in response to Leishmania major infection. Infection and Immunity, 68(4):1773-1780.

Mohrs, M., Lederman, B., Köhler, G., Dorfmüller, A., Gessner, A., Brombacher, F. 1999. Differences between IL-4- and IL-4 receptor alpha-deficient mice in chronic Leishmaniasis reveal a protective role for IL-13 receptor signalling. Journal of Immunology, 162(12):7301-7308.

Murphy, K. 2002. Janeway's immunobiology. Garland Science: Taylor \& Francis Group, New York.

Nacher, M., Carme, B., Sainte Marie, D., Couppie, P., Clyti, E., Guibert, P., et al. 2001. Seasonal fluctuations of incubation, healing Delays, and clinical presentation of cutaneous Leishmaniasis in French Guiana. Journal of Parasitology, 87(6):1495-1498. 
Noben-Trauth, N., Kropf, P., Müller, I. Susceptibility to Leishmania major infection in interleukin-4-deficient mice. Science. 1996 Feb; 271:987-990.

Noben-Trauth. N,, Paul, W.E., Sacks, D.L. 1999. IL-4- and IL-4 receptor-deficient BALB/C mice reveal differences in susceptibility to Leishmania major parasite substrains. Journal of Immunology, 162(10):6132-6140.

Palmer, P., Reeder, M.M. The imaging of tropical diseases. [Online]. 2007 [Cited 2014, August 10]. Available from: http://tmcr.usuhs.mil/tmcr/chapter46/leishman3.htm

Park, A.Y., Hondowicz, B., Kopf, M., Scott, P.. 2002. The role of IL-12 in maintaining resistance to Leishmania major. Journal of Immunology, 168(11):5771-5777.

Pearson, R.D., de Queiroz Sousa, A. 1996. Clinical Spectrum of Leishmaniasis. Clinical Infectious Diseases, 22:1-11.

Radwanska, M., Cutler, A.J., Hoving, J.C., Magez, S., Holscher, C., Bohms, A., et al. 2007. Deletion of IL-4Ra on CD4 T cells renders BALB/c mice resistant to Leishmania major infection PLOS Pathogens, 3(5):1-24.

Reithinger, R., Dujardin, J., Louzir, H., Pirmez, C., Alexander, B., Brooker, S. 2007. Cutaneous Leishmaniasis. Lancet Infectious Diseases, 7:581-596.

Reithinger, R., Mohsen, M., Wahid, M., Bismullah, M., Quinnell, R.J., Davies, C.R., et al. 2005. Efficacy of thermotherapy to treat cutaneous Leishmaniasis caused by Leishmania tropica in Kabul, Afganistan: a randomised, controlled trial. Clinical Infectious Diseases, 40(5):1148-1155.

Sacks, D., Noben-Trauth, N. 2002. Susceptibility and resistance to Leishmania major infection in mice. Nature Reviews Microbiology, 2:845-858.

Sadick, M.D., Heinzel, F.P., Holaday, B.J., Pu, R.T., Dawkins, R.S., Locksley, R.M. 1990. Cure of murine Leishmaniasis with anti-interleukin 4 monoclonal antibody: evidence for a $T$ cell-dependent, interferon gamma-independent mechanism. Journal of Experimental Medicine, 171:115-127. 


\section{http://journals.uct.ac.za/index.php/UR \\ DOI 10.15641/ur-at-uct.v1i1.29}

Scott, P., Eaton, A., Gause, W.C., di Zhou, X., Hondowicz, B.1996. Early IL-4 production does not predict susceptibility to Leishmania major. Experimental Parasitology, 84(2):178-182.

Sypek, J.L., Chung, C.L., Mayor, S.P., Subramanyan, J.M., Goldman, S.J., Sieburth, D.S., et al. 1993. Resolution of cutaneous Leishmaniasis: Interleukin 12 initiates a protective $T$ helper type 1 immune response. Journal of Experimental Medicine, 177(6):1797-1802.

Warburg, A., Saraiva, E., Lanzaro, G.C., Titus, R.G., Neva, F. 1994. Saliva of Lutzomyia longipalpis sibling species differs in its composition and capacity to enhance Leishmaniasis. Philosophical Transactions of the Royal Society B, 345:223-230.

World Health Organisation. 2014. Leishmaniasis. Available from: http://www.who.int/tdr/diseases-topics/leishmaniasis/en/ · [29 July 2014].

World Health Organisation. 2014. Media centre: Leishmaniasis. Available from: http://www.who.int/mediacentre/factsheets/fs375/en/ (2). [30 July 2014].

World Health Organisation. 2014. Neglected tropical diseases: the 17 neglected tropical diseases. Available from: http://www.who.int/neglected diseases/diseases/en/ (3). [6 August 2014].

World Health Organisation. 2002. World health report: statistical annex. Available from: http://www.who.int/whr/2002/en/whr02 annex en.pdf (4). [6 August 2014].

World Health Organisation. 2014. Global health observatory: map gallery. Available from: http://gamapserver.who.int/mapLibrary/app/searchResults.aspx (5). [6 August 2014]. 